\title{
Gabriel Marcel and the Possibility of Non-anthropocentric Hope in Environmental Education
}

\author{
Oded Zipory \\ University of Dayton
}

\section{INTRODUCTION}

Educating without hope seems impossible, and environmental education is no exception. The challenges that hope faces in regard to environmental issues are unique; the severity, scope, and complexity of current crises make dealing with climate change, threats to biodiversity, and other pressing problems, both very urgent and extremely difficult. In the face of such challenges, despair is likely to arise, and hope, while conceived as "imperative,"

Among various strategies of coping with the environmental crisis, such as legislation, international production and trade agreements, and focused scientific research, it is mainly environmental education that is assigned with the responsibility of encouraging hopeful action. Through educational efforts, we wish our students to take responsibility for their environment, and not give up on the possibility of its survival and flourishing. In general, teachers wish to provide the student with in-depth knowledge of environmental issues and with the necessary skills to choose, devise, and use various strategies to interact with the environment in a way that at least reduces the danger. Most importantly, and unlike in traditional science education, environmental education also aims at inducing personal and communal hope about the environment's future and a moral commitment to secure it. Educators encourage students to believe that their actions can and will make a difference; that despite the horrifying facts, hope is not lost, there is still much to do. 
However, hope in this difficult situation, necessary as it may be, is not flawless, and I believe it should not be taken as self-evident good. The questions we should ask are not only whether environmental educators succeed in this mission of inspiring hope in their students or how "effective" this hope is, but more importantly: What are the characteristics of this hope? What are its specific goals? What conception of nature-human relations is it based on? And ultimately, what are its possible drawbacks and faults?

In this essay I argue that the hope employed and celebrated by most projects of environmental education falls within what the French existentialist philosopher and theologian Gabriel Marcel describes as technical hope or hope as a problem. As such, it is incapable of dealing with various challenges posed by environmental crises, and might lead students and teachers to the opposites of hope-wishful thinking, naïve optimism, passive acceptance of social-environmental reality, and perhaps, even despair. Moreover, not only is environmental action itself that is undermined by the appeal to technical hope, but also the educational practices that encourage it. Instrumentalized by technical hope, environmental education tends towards sentimentalism and moralism.

Following Marcel, I argue for a different kind of hope - bope as a mystery, a mystery that involves the human and the non-human instead of looking at hope as a sort of problem-solving mechanism. This radical kind of hope is possible once the environmental question itself is reframed and anthropocentric approaches are rejected. I believe that environmental education informed and motivated by hope as a mystery could prove more immune to disappointment and apathy than the currently dominant technical hope, and deal better with pressing concerns.

In the first part of the essay, I present Marcel's critique of the connection between hope and technical orientation, and his call for hope 
as a mystery. Then, I briefly look at the state of hope in environmental education, and argue that in order for educators to adopt a non-technical view of the future, the relationship between humans and their surroundings should be reframed through a non-anthropocentric approach. Specifically, I suggest that environmental issues are not problems of resource management as commonly conceived. I show that Marcel's hope aligns with an alternative view of human/non-human relations, and I conclude by providing an example: the Japanese satoyama movement, which seeks to enliven the local pine forests and the way of life that sustains them.

\section{MARCEL'S CONCEPT OF HOPE AS A MYSTERY}

In his essay on the metaphysics of hope, Marcel critiques the technical approach to the question of hope, and asks us to view hope as a "mystery and not a problem."2 Being a mystery, hope stands outside calculations, and it is not a "practical little problem of probabilities," as he calls it. ${ }^{3}$ It simply does not "lend itself to a calculation of possibilities on the basis of accepted experience." In a sense, the term I choose here for reasons of clarity - technical hope - is misleading because

hope is not interested in the how: and this shows how fundamentally untechnical it is, for technical thought, by definition, never separates the consideration of ends and means. An end does not exist for the technical, if he does not see approximately how to achieve it. ${ }^{4}$

In opposition to the technical assertion that "I hope that so and so will take place," Marcel calls for an absolute affirmation of "I hope," lacking any definite objects of desire. The existential articulation "I hope," has, therefore, nothing to do with calculation. Since the objects of desire are unknown, at least in detail, no probability can apply to them. 
In his book, Radical Hope: Ethics in the Face of Cultural Devastation, Jonathan Lear makes a similar point about hope's breakdown with calculation and its inability to be directed towards predetermined ends. $\mathrm{He}$ argues that with radical hope not only is achieving the goals uncertain and difficult, but also the goals themselves are simply outside what the hopeful person is able to picture:

What makes this hope radical is that it is directed toward a future goodness that transcends the current ability to understand what it is. Radical hope anticipates a good for which those who have the hope as yet lack the appropriate concepts with which to understand it. ${ }^{5}$

Technicality, or choosing the right means towards desired ends, is, therefore, completely impossible when the ends are unknown. Instead of probability calculations, hope requires "a commitment to the idea that the goodness of the world transcends one's limited and vulnerable attempts to understand it." ${ }^{\prime 6}$

How would this hope as a mystery look? And what exactly does it mean to radically hope for something I do not yet know? Marcel describes three important characteristics of the non-technical "I hope":

1. Patience and effortlessness -For Marcel, the temptation to resist despair in dire situations does not involve any "sense of effort," and such a feeling is incompatible with hope in its purest form. He explains that these wrong efforts are intended to force one's personal rhythm on the rhythm of events beyond his reach, and thus create the common feeling of impatience. Alternatively, in hope as a mystery, one should wait for events to unfold in their own time. ${ }^{7}$

2. Communion of self and non-self - Unlike the optimist, who considers things from a distance and "remains in the province of the 'I myself',", 
Marcel's hopeful individual is involved in the situation and not just spectating it. Marcel writes:

A problem is something which I meet, which I find completely before me, but which I can therefore lay siege to and reduce. But a mystery is something in which I am myself involved, and it can therefore only be thought of as a sphere where the distinction between what is in me and what is before me loses its meaning and initial validity.

In radical hope a clear separation between human and non-human is no longer possible, nor is it desired. Deliverance from a dire situation is not only projected outside towards the circumstances, nor only towards objective "things," but also towards the inner self. Marcel writes: "In hoping, I develop in connection with the event and perhaps above all through what it makes of me, a type of relationship, a kind of intimacy comparable to that which I have with the other person when I am patient with him."10

While radical hope is associated with an indistinction between, or better said, a communion of self and non-self (whether it is with God, with nature, or with another person), despair is associated with isolation, and Marcel even wonders whether they are in fact identical. ${ }^{11}$ In refusing the "not me," or in trying to control it, I captivate myself within my own heavily guarded walls. I am giving in to the "temptation of shutting the door which encloses me within myself and at the same time encloses me within time, as though the future, drained of its substance and its mystery, were no longer to be anything but a place of pure repetition." ${ }^{12}$ In hope of the mysterious, radical kind, the hopeful person, her object of hope, and the challenges she faces, are all intertwined and changing together.

3. Inability and refusal to imagine future prospects - For Marcel, the situation of not being able to comprehend future goodness, as also described earlier by Lear, is not restricted to catastrophes but is ever-present, 
although not in a self-evident or obvious way. It is not naturally felt, but requires special attention. The mystery of hope involves not only rejecting technical causality in regard to achieving certain ends, but also the full determination of these ends. In other words, we know not for what we strive. Moreover, we should actively reject the temptation to "know" that. While the urge to imagine a favorable future is undeniable, Marcel sees the imagining of prospects as wrong and potentially harmful. Yes, picturing relief is perhaps a psychological necessity, but nevertheless it is still an illusion serving the temptation of despair and not a characteristic of true hope. Ultimately, envisioning future prospects must be resisted, and hope should transcend imagination. ${ }^{13}$

Refusal to imagine and plan for the object of hope renders it immune to disappointment and the true hopeful person is the one who "transcends all possible disappointment and would experience a security of his being, or in his being, which is contrary to the radical insecurity of having." "The fact that radical hope has a mysterious vision of the future is not a source of weakness, therefore, and it does not put it at a disadvantage compared to technical hopes, plans, "blueprints," or any carefully articulated utopias. Quite to the contrary, "hope draws its persuasive power from a vision yet to be unveiled."15

\section{ENVIRONMENTAL EDUCATION'S HOPE AS A PROBLEM}

We would expect this kind of hope, with its unimaginable objects, requirement for patience, and potential involvement with the non-human world, to be important for environmental education. This, however, does not happen. Being oriented towards voluntary individual action, and heavily reliant on scientific "objectivity," environmental education tends to become a project in which hope is an empty signifier and a problem-solving instrument. 
The teacher, viewing human-environment relations as a solvable problem, hopes that the student will become more aware of the issue at hand, regard it as problematic, and voluntarily take personal responsibility over reducing the severity of present situation. In order to do so, both teacher and student must be hopeful about the impact of their actions, and anything that might interfere with this hope - political disagreements, local and global inequalities, or destruction of the environment by non-individual actors such as states or big industries - are moved aside or undervalued. Environmental education becomes then a quasi-religious endeavor that is based on a romantic and sentimental identification with the earth as a whole, a sense of unity between all humans, a false conception of individual agency, and a naïvely optimistic view according to which the crisis will eventually be overcome, if only we were to become more hopeful and more responsible. In short, as the environmentalist educator and scholar John Huckle indicates, environmental education becomes "an evangelical mission. People are to be converted; their hearts and minds, their values changed." 16

Nothing exemplifies the pastoral nature of environmental education, as well as its notable success, better than the practice of recycling. I see recycling as paradigmatic for environmental education as it involves scientific knowledge, skills, and moral attitudes; it is necessarily tied to individual action, and it requires personal responsibility for the future. Recycling, much like environmental education in general, is understood as clearly a good thing. It is beyond controversy. While students and the public become increasingly committed to reduce, separate, and recycle their waste, there are serious doubts about the effectivity or even rationality of recycling. ${ }^{17}$ These doubts, however, do not seem to have any impact. When trying to explain why "zero-waste" policies continue to be advanced despite objections from pro-environment scientists, New York Times author John Tierney addresses the sentiments tied to recycling: "Recycling 
intuitively appeals to many voters: it makes people feel virtuous. ... It is less an ethical activity than a religious ritual, like the ones performed by the Catholics to obtain indulgences for their sins." 18 The problem, then, is that environmental education in this optimistic, technically-hopeful, "evangelical" form is unfit to deal with these questions, and probably with many more besides.

\section{HUMAN/NON-HUMAN RELATIONSHIPS AS A CONFRONTATION WITH THE MYSTERY OF RESURGENCE}

Taking a step back from recycling to a more general view of environmentalism, I contend that as long as our relationship with the environment is framed as a "problem" between two distinct entities, hoping in a technical manner is probably the right and only thing to do.

Yet there are different ways to understand human/non-human relationships. A useful distinction would be between the common way of understanding the current crisis as primarily a question of resource management, and an alternative view of it as a confrontation with the mystery of resurgence. According to the first view, the natural world is a collection of resources we should use wisely so they will not be totally consumed. Even if we assign nature with intrinsic value (for example, if we believe that animals or rivers make our life fuller simply because of what they are, not only due to their practical use), nature is still regarded as a potentially perishable resource that, hopefully, will be managed less poorly. Environmental challenges are, in this view, basically technical. Although solving these problems might require us to employ non-technical traits such as moral strength, wise political decision-making, and scientific creativity, at their core they still are questions of choosing the correct means to achieve the goal of sustaining the world as a viable resource. Hope in the resource management approach is therefore ultimately technical. 
As for the alternative, the etymologic root of the word "resource" implies a more fundamental question we face, and calls for a different kind of hope. In his article "Salmon of the Heart," Tom Jay traces "resource" back to the religious attitude towards nature:

In current usage, "resource" means raw material or potential energy. We have resource planning, resource development and resource allocation. In our day "resource" denotes an energized plastic something we practice our clumsy cleverness on. But beneath current usage lies a deeper religious information. Etymology reveals that "resource" derives from "surge" and "re." "Re" means back, return, refund. ... Surge is a contraction of Latin subregere, to rule or direct from below. In its root sense, its heart sense, "resource" is a recurring directed energy sent by powers hidden from view. A "resource" surges back, sent by a hidden power. ${ }^{19}$

Following this short inquiry, we could understand the environmental crisis not as the consequence of natural resource mismanagement, but as an enduring challenge of living with the mystery of natural resurgence. As such, it primarily concerns the loss or potential loss of life, whether we are talking about the loss of individual lives, the loss of life forms, or the loss of our beloved life styles, our "life as we know it."

More reasons to depart from the resource management approach come from contemporary critiques of mainstream environmental ethics, and, in particular, critiques on environmental ethics' (and environmental education's) anthropocentrism. In general, postmodern critiques of environmental ethics target the modern assumption that man is separate from and in control of nature, his mind "grown above nature." ${ }^{20}$ Special attention is given by these critiques, then, to reformulating the interac- 
tions between humans and the non-human world from a perspective that does not privilege the former nor does it view the human as completely distinct from its surroundings. Where traditional environmental ethics ask about humans' responsibility over their environment and in what ways it should be taken, postmodern theories call into question the very boundary between these allegedly separate realms. Or as Tony Fry and Anne-Marie Willis put it: "we must recognize that there is no 'outside' from which to speak or act; we must gain a new normative matrix for the conception and production of the world." 21

If we are to accept this indistinction between human and non-human, and view the environmental crisis as a threat to the resurgence of nature - human life included - then the important implication is that environmental education does not concern technical issues or, at least, it does not only concern problems to be solved by employing the correct means. Developing a different approach towards nature will require hope that transcends technicality and radically involves the hopeful teacher and student with the mystery of what Jay calls "powers hidden from view." 22

Marcel's hope seems fit for a non-anthropocentric environmental education. First, like the postmodern critic who rejects the separation between the human self and the environment, the student sees it as a mystery in which he is necessary involved, instead of viewing it as a problem fully posed before him. A sense of communion between self and the world could then replace or substantiate differently students' sense of moral responsibility for their surroundings. Second, hopeful environmental actions will be taken patiently, in Marcel's sense of the word; meaning, not enforcing one's individual rhythm on the unique rhythm of the other, i.e., nature's own pace. Third, and finally, the unimaginability of mysterious hope and its rejection of predetermined ends seems to be the only viable answer to the question raised by Lear: How can we both remain ourselves 
and survive without one goal undermining the other ${ }^{23}$ Regarding our environmental situation, and assuming we reject both accelerated modernism in the form of technological optimism and pre-modernity in the form of a romantic "return to nature," the basic question we need to ask is: How can we remain our modern selves while not destroying the very things that enable our survival? This question simply cannot be answered as a technicality of means and ends; we cannot imagine or conceptualize the answer at this point nor can we know what our goals should be. Moreover, we should reject definite ends that promise to "solve the problem," such as slogans like "sustainable development," "zero-waste," and others. At least we can be aware of the dangerous temptation they present.

\section{HOPING FOR MUSHROOMS (AND HUMANS)}

To conclude, I want to speak a little about mushrooms with reference to the example of the Japanese satoyama movement.

Originally, satoyama means the management of forests, foothills, and fields by local farmer communities. Specifically, it is the practice that allowed farmers to supplement their livelihood by use of the forest, for example, by collecting young and fallen leaves as fertilizer for their fields, collecting wood for charcoal and construction, or gathering mushrooms. The result of these centuries-old practices is a fascinating ecosystem natural, yet with "human touch written all over it." 24 Rapid urbanization, shifting from charcoal to other resources, and the use of chemical fertilizers, have caused the satoyama forests to gradually disappear, and their characteristic pine trees to become extremely rare.

In the 1980s and 1990s a movement to revitalize these ecosystems emerged in Japan, with hundreds of groups calling for a livelihood that is harmonious with nature and biodiversity, and that goes hand in hand 
with human well-being. One of the symbols of this movement, perhaps the most prominent one, is the popular matsutake mushroom, which forms a symbiotic relationship with the pine trees. Due to the decline of the satoyama forests and of the pines, the mushroom, once common in Japan, is now harvested elsewhere and shipped to Japan where it is sold at amazingly high prices. In a way, the efforts of the satoyama volunteers are directed towards and culminate in the matsutake, and its reemergence is, for them, the most notable sign of success. The motto of the Kyoto satoyama volunteers, for example, is "let's revitalize the forest, so we can all eat sukiyaki [typical dish with mushrooms]." Strange as this crusade might seem at first, there is much to be learned from this initiative and from its underlying assumptions regarding hope, human agency, uncertainty, and the renewal of the non-human as well as the human.

In her book The Mushroom at the End of the World: On the Possibility of Life in Capitalist Ruins, the anthropologist Anna Tsing studied the satoyama activists, and the challenges they face. ${ }^{25}$ According to Tsing, the basic problem with revitalizing a forest is that it cannot be addressed in a strictly technical manner. Because this ecosystem is a complex assemblage of human and many non-human species, exact predications about the chances of success are almost impossible. Radical hope is a must. In other words, revitalizing a forest is fundamentally different from growing a garden. Unlike the mainstream Western conception of preservation according to which forests are better off left alone, the Japanese pine forests suffer from under-use; they require human action and they die without it. Yet, unlike in gardening, these actions are never simple means towards ends. In their indirectness they refuse technicality.

The dichotomy between the human and the non-human is but one of many that satoyama work undermines, and hope's communal characteristic is shown here in more than one way. Another that is perhaps 
closer to education is the close relationship between scientific knowledge and the knowledge held by elderly farmers. ${ }^{26}$ And yet another dichotomy that proves unfit for describing the satoyama movement is the one between work and leisure or doing and learning. Tsing quotes a volunteer saying, "There is more involved than helping out peasants - and pines. Satoyama work remakes the human spirit." ${ }^{27}$ By working together, the satoyama activists are turning the forest into a site of true re-creation, in the fullest sense of the word.

Looking more closely at the Satoyama's "goal" - the desired mushroom - it's clear that this is a very strange object for hope. A hybrid of living organism and plant, it is ephemeral and no long-term benefits can be gained from it. In its temporality and short life span the mushroom symbolizes not a "back-to-nature" redemption, but a momentary achievement in "picking through the heap of alienation," as Tsing puts it. ${ }^{28}$ Moreover, the matsutake encapsulates an element of unpredictability that cannot be diminished or overcome. The volunteers have no way of knowing if the mushrooms will appear when expected; all they can do is hope that their actions have somehow contributed. Relinquishing the notion of progressive advancement leads to a focus on the "livable hereand-now," and allows the volunteers to act, and to educate themselves and others, without "knowing where the world-in-process is going." 29

Finally, the hope of the satoyama volunteers suggests another promising contribution to environmental education. While now it is focused on moral obligations (often accompanied by a feeling of guilt), hope as a mystery could open environmental education to feelings of joy, self-fulfillment (better said, mutual-fulfillment), and belief in the ability of the world to become radically different from what we expect it to be. Adopted by educators, radical, mysterious hope could help in transforming environmental education from a moralistic, "evangelical" 
work into a different kind of engagement with ourselves and with our surroundings - human and non-human. Perhaps then we will be better suited to deal with a crisis, which is environmental but also social and political, as compelling as the one we are facing.

1 Taken from the title of the influential educator and environmental activist David Orr's essay collection, Hope Is An imperative: The Essential David Orr (Washington, DC: Island Press, 2011).

2 Gabriel Marcel, Homo Viator; Introduction to a Metaphysic of Hope, trans. Emma Craufurd (London: Gollancz, 1951), 35.

3 Ibid., 29.

4 Ibid., 51.

5 Jonathan Lear, Radical Hope: Ethics in the Face of Cultural Devastation (Cambridge, MA: Harvard University Press, 2006), 103.

6 Ibid., 95. David Halpin also differentiates between "ultimate" and "absolute" hope, in a way that echoes, and is to some extent based upon, Marcel's conception of hope. David Halpin, Hope and Education: The Role of the Utopian Imagination (London: Routledge, 2003).

7 Ibid., 36.

8 Ibid., 34.

9 Gabriel Marcel, Being and Having: An Existentialist Diary (New York: Harper \& Row, 1965), 117, italics added.

10 Marcel, Homo Viator, 40.

11 Ibid., 58.

12 Ibid., 60.

13 Marcel, Homo Viator, 45.

14 Ibid., 46.

15 Verena Kast, Joy, Inspiration, and Hope (College Station: Texas A \& M University Press, 1991), 136.

16 John Huckle, “Ten Red Questions to Ask Green Teachers," Green Teacher 1, no. 2: 11-15, 13. 
17 Thomas C. Kinnaman, Takayoshi Shinkuma, and Masashi Yamamoto, “The Socially Optimal Recycling Rate: Evidence from Japan," Journal of Environmental Economics and Management 68, no. 1 (2014): 54-70.

18 John Tierney, “The Reign of Recycling,” New York Times, October 3, 2015.

19 Tom Jay, “The Salmon of the Heart," Chicago Review 37, no. 4 (1992): 20$45,22$.

20 Tony Fry and Anne-Marie Willis, "Criticism Against the Current," in Meanjin 48, no. 2 (Winter 1989): 223-240.

21 Ibid., 230.

22 Jay, "The Salmon of the Heart," 22.

23 According to Lear, this is the question that was posed before the Crow nation more than a century ago, and that led their chief Plenty Coups to radical hope.

24 Masumi Mizunuma (director), Satoyama: Japan's Secret Water Garden (NHK, 2004).

25 Anna Lowenhaupt Tsing, The Mushroom at the End of the World: On the Possibility of Life in Capitalist Ruins (Princeton University Press, 2015).

26 Ibid., 263.

27 Ibid., 262.

28 Ibid., 264.

29 Ibid., 161, 264. 